Journal of Case Reports 2017;7(2):130-132

\title{
Primary Ovarian Ectopic Pregnancy
}

\author{
Bhoomika Tantuway, Poonam Sachdeva, Reva Triapthi, YM Mala \\ Department of Obstetrics and Gynaecology, Maulana Azad Medical College and Lok Nayak Hospital, New Delhi, 110002, India.
}

\section{Corresponding Author:}

Dr. Bhoomika Tantuway

Email: drbhoomi_2005@yahoo.co.in

This is an Open Access article distributed under the terms of the Creative Commons Attribution License (creativecommons.org/ licenses/by/3.0).

Received : November 26, 2016

Accepted : February 14, 2017

Published : April 5, 2017

\begin{abstract}
Background: Incidence of ovarian ectopic pregnancy is about $0.001 \%$ to $0.013 \%$ of normal pregnancies. Pregnancy with Copper $\mathrm{T}$ device in-situ comes with increased chances of ectopic pregnancy. Case Report: A 23-year lady with intrauterine copper-T device $(\mathrm{Cu}$ T 380A) in-situ, presented with complaint of pain in lower abdomen. There was no history of overdue of menstruation. Her urine pregnancy was positive, per vaginum examination showed tenderness and fullness in right fornix, $\beta \mathrm{HCG}=4300$, ultrasound showed free fluid in pouch of Douglas. Laparotomy showed hemoperitoneum and ruptured right ovarian ectopic pregnancy. Wedge resection and reconstruction of ovary was done. Histopathological examination confirmed ovarian ectopic pregnancy. Conclusion: Recognizing ovarian ectopic pregnancy is of critical importance, and should be considered in the differential diagnosis of acute abdomen in women of reproductive age.
\end{abstract}

Keywords: Abdomen, Ectopic Pregnancy, Intrauterine Devices, Laparotomy, Ovary, Pregnancy.

\section{Introduction}

Primary ovarian ectopic pregnancy is very rare condition, its incidence is about $0.001 \%$ to $0.013 \%$ $[1,2]$. Use of copper $\mathrm{T}$ device is suggested risk factor for ovarian ectopic pregnancy. Diagnosis is made using the Spiegelberg criteria [3] which includes: (i) gestational sac located in the region of the ovary, (ii) ectopic pregnancy is attached to the uterus by the ovarian ligament, (iii) ovarian tissue in the wall of the gestational sac is proved histologically, (iv) tube on the involved side is intact.

Prior to surgery, diagnosis of ovarian ectopic is seldom made, even transvaginal sonography is not very much useful for diagnosing this condition. We are reporting this case of ovarian ectopic pregnancy associated with IUCD (intra uterine copper T device) use, justifying that IUCD is one of the risk factor of ovarian ectopic pregnancy.

\section{Case Report}

A 23 year old patient presented with complaint of pain in lower abdomen. There was no history of overdue of menstruation. She had regular menstrual cycle of 4 days in 28 days cycle. She had last menstrual period 24 days prior to presentation with an average flow. Patient had two live children, last child birth was 2 years back. She got IUCD $(\mathrm{Cu}$ T 380A) inserted 6 months back. On examination, her vitals were stable, pulse rate $92 /$ minute, blood pressure was 100/60 mmHg. On per abdomen examination, tenderness, guarding and rigidity was absent. Per speculum examination revealed healthy cervix and vagina, no bleeding and copper $\mathrm{T}$ thread was seen. On per vaginum examination no cervical motion tenderness, normal sized anteverted uterus with backward cervix, mildly tender full right fornix was present. Urine pregnancy test was positive, and $\beta$-HCG was $4300 \mathrm{IU} / \mathrm{L}$ (normal: $<5$ IU/L). Ultrasonography showed normal uterus, 
bilateral bulky ovaries, no obvious adnexal mass, and free fluid in pouch of Douglas and in pelvis.

Decision for laparotomy was taken as pain has increased and tachycardia occurred. Hemoperitoneum of $600 \mathrm{ml}$ was evident. The site of ectopic pregnancy was identified over right ovary, $2 \times 2 \mathrm{cms}$, with bleeding from its surface. Uterus, bilateral fallopian tubes and left ovary were normal [Fig.1,2]. Wedge resection of ovary was done, removing the ectopic mass and reconstruction of ovary was done [Fig.3]. Post-operative period was uneventful. Histopathological examination of ectopic mass shows an ovarian ectopic pregnancy.

\section{Discussion}

Ovarian pregnancies are about 1-3\% of all ectopic pregnancies. Suggested risk factors are younger age, endometriosis, pelvic inflammatory disease, intra-uterine devices, ovulatory medications, and assisted reproductive techniques [3]. In present case report, IUCD was found to be risk factor for ovarian ectopic pregnancy. IUCD prevents uterine implantation, tubal implantation by $99.5 \%$ and $95 \%$ respectively, without any effect on ovarian ectopic pregnancy [3-6]. Pre-surgical diagnosis of ovarian ectopic pregnancy is difficult, even ultrasonography or trans-vaginal sonography can misdiagnose it for haemorrhagic corpus luteum or ovarian cyst.

Ovarian ectopic pregnancy can be treated conservatively with single dose methotrexate. But preferred mode of treatment is surgical by either laparotomy or laparoscopy [7]. In the past, ovarian pregnancy had been treated by ipsilateral oophorectomy, but trend has been shifted toward conservative surgery such as cystectomy or wedge resection performed by either laparotomy or laparoscopy. Currently, laparoscopic surgery is the treatment of choice [8]. Future fertility is not affected after ovarian pregnancy [7]. In our patient, laparotomy was performed because of hemoperitoneum and with deteriorating vitals of patient.

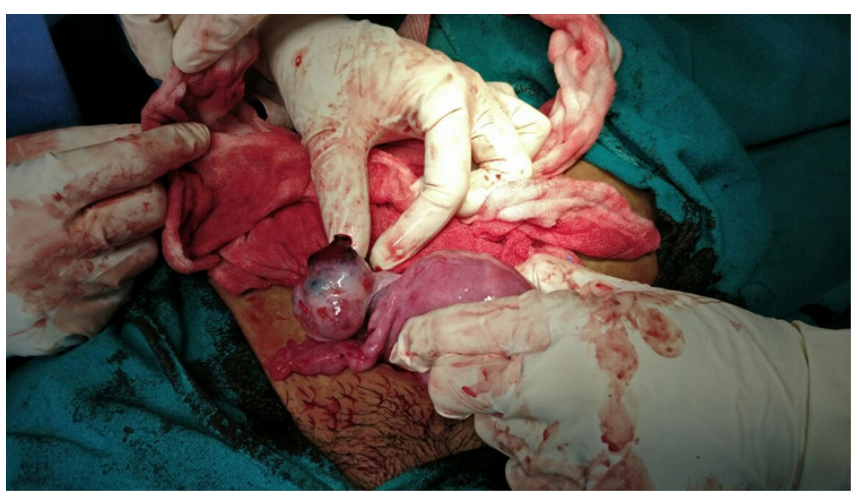

Fig.1: Site of ectopic pregnancy was identified over right ovary.

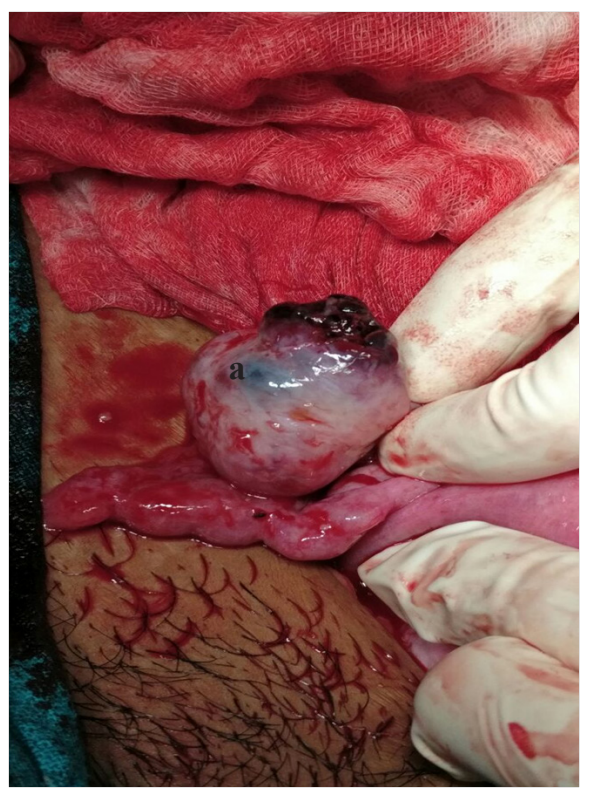

Fig.2: Zoomed view of figure 1 - right ovarian ectopic pregnancy.

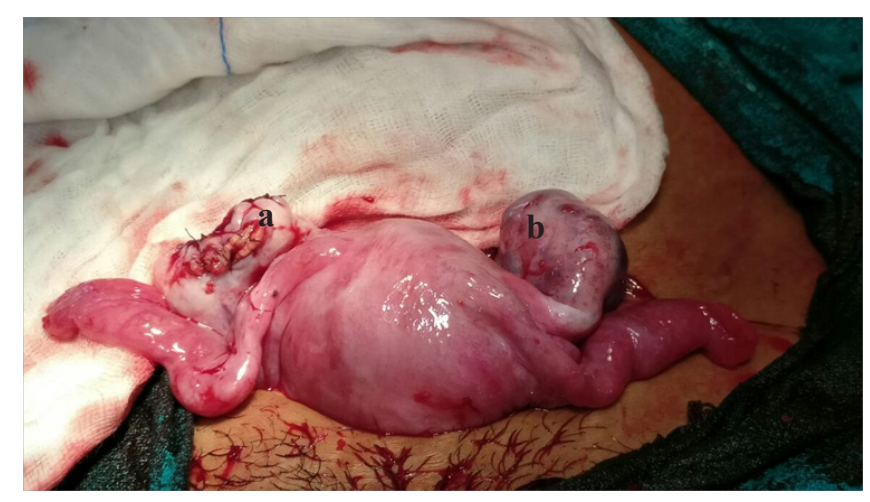

Fig.3: a: reconstructed right ovary after wedge resection. b: left ovary. 


\section{Conclusion}

Ovarian ectopic pregnancy is rare, but it should be considered in the differential diagnosis of acute abdomen in women of reproductive age.

Contributors: BT: Manuscript writing and literature review; PS, RT, YMM: Manuscript revision and literature review. All authors were involved in case management. BT will act as guarantor. All authors approved the final version of the manuscript.

Funding: None; Competing interests: None stated.

\section{References}

1. Mitra J, Das PC. Primary ovarian pregnancy (with a case report). J Obstet Gynaecol India. 1973;23:509-513.

2. Sakunthaladevi, Reddy I, R. S., Reddy DB. Ovarian pregnancy. J Obstet Gynaecol India. 1967;17:314-321.

3. Sandvier Sandstad E, Steir JA. Ovarian pregnancy associated with intrauterine contracepyive device. Acta
Obstet Gynecol Scand. 1987;66:137-141.

4. Ciortea R, Costin N, Chiroiu B, Malutan A, Mocan R, Hudacsko A, et al. Ovarian pregnancy associated with pelvicadhesions. Clujul Med. 2013;86:77-79.

5. Joseph RJ, Irvine LM. Ovarian ectopic pregnancy: aetiology, diagnosis, and challenges in surgical management. J Obstet Gynaecol. 2012;32:472-474.

6. Das S, Kalyani R, Lakshmi M, Kumar Harendra ML. Ovarian pregnancy. Indian J Path Microbiol. 2008;51:3738.

7. Panda S, Darlong LM, Singh S, Borah T. Case report of a primary ovarian pregnancy in a primigravida. J Hum Reprod Sci. 2009;2:90-92.

8. Rashmi B, Vanita S, Preeti V, Seema C, Jasvinder K. Failedmedical management in ovarian pregnancy despite favorable prognostic factors: A Case Report. Med Gen Med. 2006;8:35.

9. Shinde S, Aher G, Gavali U. Case report of primary ovarian ectopic pregnancy. Int J Healthcare Biomed Res. 2015;3:68-70. 